\title{
SISTEMAS DE ESPAÇOS LIVRES DE FLORIANÓPOLIS (SC) \\ A estruturação da base de dados como ferramenta de gestão pública
}

\author{
OPEN SPACE SYSTEM OF FLORIANÓPOLIS \\ Structuring the database as a public management tool
}

\author{
A. Elisa Beck \& B. Larissa Trindade \\ IPUF, Instituto de Pesquisa e Planejamento Urbano de Florianópolis; Florianópolis, Brasil \\ elisa.ipuf@gmail.com \\ larissa.ipuf@gmail.com
}

\author{
C. Daniel Silveira \& D. Natália Ferreira \\ UFSC, Universidade Federal de Santa Catarina; Florianópolis, Brasil \\ danielmartinsdasilveira@gmail.com \\ nataliabaltens@gmail.com
}

\section{RESUMO}

O Instituto de Pesquisa e Planejamento Urbano de Florianópolis (IPUF) tem realizado o levantamento e a análise do Sistema de Espaços Livres de Florianópolis, Santa Catarina - Brasil. Este artigo aborda as etapas de sistematização, análise e divulgação das informações referentes à Rede de Espaços Públicos (REP), constituída pelos espaços livres de uso público de lazer e recreação. $O$ trabalho envolveu a identificação, estruturação, classificação e divulgação de um banco de dados em ambiente SIG. Foram realizadas análises espaciais e quantitativas, apoiadas em mapas temáticos que agregam dados populacionais e econômicos. Constata-se uma desigualdade espacial e socioeconômica na oferta da infraestrutura de espaços livres públicos com uso de lazer, concentrada nas regiões com maior renda per capita e na porção mais central do território. É ressaltada a importância da sistematização dos dados e da continuidade das análises, de modo a orientar as ações do planejamento e da gestão municipal.

Palavras-chave: Sistemas de Espaços Livres, Espaços Públicos, Rede de Espaços Públicos

Linha de Investigação: 1: Cidade e projeto

Tópico: Planeamento, políticas y governança 


\section{XII $\square$ SÃO PAULO $15 \sim 17 \cdot$ LISBOA $25 \sim 26$ JUN 2020}

\section{ABSTRACT}

The Institute of Research and Urban Planning of Florianópolis (IPUF) is conducting the survey and analysis of the Open Space System of Florianópolis, Santa Catarina - Brazil. This paper outlines the stages of data gathering, analysis and publicity regarding the Public Spaces Network (REP), constituted by open spaces with public use for leisure and recreation. The work involved the identification, structuring, classification and dissemination of a database in a GIS environment. Spatial and quantitative analysis were carried out, supported by thematic maps that aggregate population and economic data. There is a spatial and socioeconomic inequality in the provision of infrastructure for public open spaces with leisure use, concentrated in the regions with the highest per capita income and in the most central part of the territory. The importance of database improvement and continuity of the analysis is highlighted in order to guide the actions of municipal planning and management.

Keywords: Open Space System, Public Space, Public Spaces Network

Research line: 1: City and project

Topic: Planning, policies and governance

\section{INTRODUÇÃO}

A produção do espaço urbano é o resultado da dinâmica dialética dos elementos ativos do espaço, os homens, as instituições e as empresas, com os processos naturais do território (Santos, 2006). O modo de viver moderno é amparado por infraestruturas públicas socialmente criadas, distribuídas dentre os sistemas urbanos e geridas pelo poder público. Essa rede de espaços e equipamentos é interligada por meio do sistema viário e pelas infraestruturas verde e cinza (Herzog e Rosa, 2010), constituindo relações interespaciais nas superfícies não edificadas de uso público e privado da cidade.

Nesse sentido, o Sistema de Espaços Livres (SEL), que reúne os espaços não edificados ou com baixa proporção de elementos construídos (Magnoli, 1982), cumpre um papel fundamental na promoção da qualidade de vida dos cidadãos, contribuindo para o lazer, conectividade e conservação ambiental. Assim, compreender a configuração, a distribuição e a utilização do conjunto dos espaços não edificados de uma cidade é fundamental para orientar as atividades de planejamento e gestão urbana.

Espaços livres são todos aqueles não contidos dentro das áreas construídas, como "as ruas, praças, pátios, quintais, parques, jardins, terrenos baldios, corredores externos, vilas, vielas" (Macedo, 1995: 16). É possível detectar e analisar tipologias e configurações de espaços livres característicos de cada realidade urbana, partindo-se da premissa de que estes atendem ao interesse público, não sendo, contudo, necessariamente um bem público. Dessa forma, as análises do sistema podem envolver outras espacialidades de uso público, como igrejas, espaços comerciais, praias, estádios, dentre outros, conquanto sejam acessíveis e funcionais aos cidadãos e transeuntes. Como também indica Macedo (2018),

propõe-se um conceito mais abrangente que extrapola limitações físicas de conexão e distância. Não há tipo único ou ideal de sistema, pois cada cidade possui características específicas de tecido urbano em função de sua formação histórica, características socioeconômicas, localização geográfica e suporte físico. 
A classificação dos espaços livres é uma tarefa necessária para o entendimento global do SEL, e deve ser ponderada a sua função, sua morfologia e apropriação de uso pelos cidadãos. Magnoli (2006) toma como partida as normas californianas para, a partir delas, compor um espectro de categorias adequadas para cada espaço. Essas categorias indicadas dividem-se em seis grandes grupos, baseadas no papel que cumprem dentro dos sistemas urbanos: a produção de recursos (como terras agrícolas, barragens, áreas de mineração), a proteção de recursos naturais e culturais (zonas históricas ou culturais, reservas naturais), usos sanitários e sociais (lazer, depósito de lixo, circulação), segurança pública (zonas de deslizamentos, riscos de incêndio, sobrevoo de aeroportos), equipamentos públicos e corredores urbanos (linhas de alta tensão, vias e canais). A autora indica, ainda, uma possível sobreposição de funções para um único espaço, de modo que essa distribuição compreenda a maior parte de mecanismos da cidade.

Ao abordar os espaços livres de lazer, Macedo (1995) orienta que a análise do SEL não deve ser restrita aos indicadores de proporção de áreas de lazer/vegetação por habitante, uma vez que este dado é pouco representativo se não for associado a critérios de distribuição e acessibilidade. Da mesma forma que os aspectos quantitativos, qualitativos, ambientais e funcionais são relevantes no estudo da forma urbana, os aspectos socioeconômicos e culturais são determinantes nos usos do SEL (Macedo, 2012). Dessa maneira, o cruzamento de dados de diferentes assuntos por meio de mapas temáticos é fundamental para realizar a análise do sistema.

Conforme indica Magnoli (2006), a disponibilidade de área de espaço livre por habitante acompanha, indubitavelmente, a renda média e per capita das localidades em análise, o que dificulta atingir um consenso quantitativo ideal para um município inteiro, ou mesmo dentro de um distrito. No entanto, estes indicadores não deixam de ter sua importância para constatar a distribuição, ou mesmo a existência, desses tipos de espaços. Outros parâmetros relevantes dizem respeito à acessibilidade. Byrne e Sipe (2010), indicam raios caminháveis e cicláveis como indicadores de proximidade adequada entre o espaço e o usuário. Para a zona do caminhar, indicam-se distâncias de 400 metros para idosos ou adultos fora de forma e 800 metros para adultos em boa forma, e dez minutos de caminhada para ambos. Já a zona do pedalar é definida por dois quilômetros e quinhentos metros, também no raio de dez minutos de deslocamento.

Neste contexto, o Instituto de Pesquisa e Planejamento Urbano de Florianópolis (IPUF) tem realizado o levantamento, a análise e a discussão do Sistema de Espaços Livres do município de Florianópolis, cidade litorânea e capital do estado de Santa Catarina - Brasil. Com uma população estimada em 492 mil habitantes (IBGE, 2019), Florianópolis tem uma área terrestre de $435 \mathrm{~km}^{2}$, sendo que $95 \%$ dessa área é insular, a llha de Santa Catarina (IPUF, 2004). Além disso, possui um extenso litoral banhado pelo Oceano Atlântico, na face leste, e pelas baías Norte e Sul, na face oeste do território (Fig. 01), contabilizando mais de 100 praias (IPUF, 2004). 


\section{SÃO PAULO15 17 LISBOA $25 \sim 26$ JUN 2020

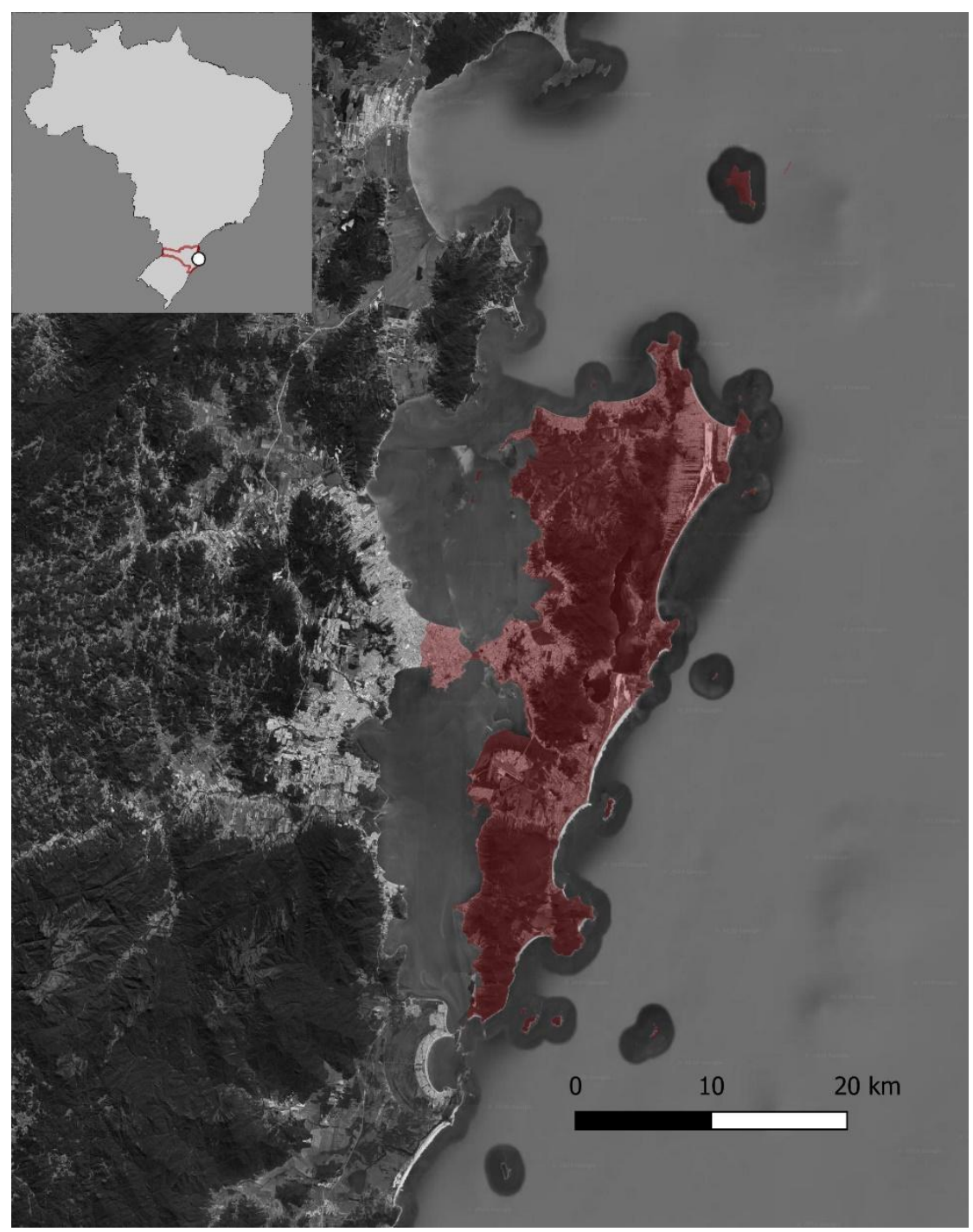

Fig. 01 Florianópolis - SC - Brasil: território municipal em destaque. Fonte: Elaboração própria a partir de dados do Google Satellite (2020).

O presente trabalho aborda a estruturação e o status atual do programa Rede de Espaços Públicos (REP), constituída pelos espaços livres de uso público. O programa é uma estratégia municipal para integrar diversas secretarias, sob a coordenação do Instituto de Pesquisa e Planejamento Urbano de Florianópolis IPUF, autarquia municipal criada no ano de 1977, e que tem sua atuação marcada nas pautas urbanas e ambientais e figura na estrutura do poder executivo como órgão responsável pela gestão do território, promovendo o planejamento integrado.

Com a implantação e desenvolvimento da REP, busca-se qualificar a gestão territorial dos espaços livres de uso público de lazer e recreação do Município, como as praças, os parques urbanos e outros espaços de 



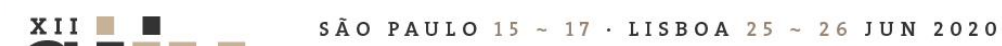

contribuição em aspectos da morfologia urbana (como o acesso à orla), possibilidades de visualização da paisagem da cidade e reserva de áreas para usos futuros (esta, incumbência de grande valor para o planejamento urbano).

As classes adotadas referem-se aos usos e funções predominantes, não sendo, contudo, excludentes de outras atividades associadas. Por exemplo, um parque municipal ambiental enquadrado enquanto Unidade de Conservação pode ter funções recreativas e um acesso à orla; pode conter equipamentos que o caracterizem, também, como um estar urbano. Portanto, para além dos parques e praças, foi necessário criar novas categorias que abrangem os diversos componentes do sistema, incluindo alamedas, largos, acessos à orla, estares urbanos, áreas de preservação ambiental, entre outros.

\subsection{Espaços Livres de Lazer e Recreação}

\subsubsection{Praças}

Espaços públicos urbanos dotados de infraestrutura e mobiliário urbano, com a função principal de lazer e recreação e com abrangência de atendimento na escala local. Compreende também os largos.

\subsubsection{Parques Urbanos}

Espaços públicos urbanos dotados de equipamentos, infraestrutura e mobiliário urbano e com abrangência de atendimento nas escalas do bairro, município ou metropolitana. São vocacionados ao lazer, esporte e recreação, por vezes agregando funções aliadas à preservação ambiental.

\subsection{3. Áreas Esportivas Abertas}

Áreas públicas abertas e equipadas, predominantemente, com estruturas esportivas. Compreende, por exemplo, campos de futebol, academias ao ar livre, quadras esportivas e pistas de skate.

\subsection{4. Áreas Públicas Destinadas ao Lazer não Equipadas - Oriundas de Parcelamento}

Áreas públicas oriundas de parcelamento do solo e com características que as tornam aptas à destinação como função principal de lazer e recreação, contudo, ainda não implantadas ou equipadas. Conforme suas características, estas áreas podem se tornar futuras praças ou parques.

Salienta-se que áreas que, porventura, foram designadas em loteamentos como "Área Verde" ou "Área Verde de Lazer", mas que não possuem características adequadas para o uso principal de lazer, não estão listadas nesta categoria. Nestes casos, essas áreas foram enquadradas, por exemplo, nas classes "Áreas com Vegetação Relevante" ou "Outras Áreas".

Da mesma forma, áreas de parcelamento já implantadas e equipadas encontram-se nas classes "Praças", "Parques" ou "Áreas Esportivas Abertas". 


\section{SÃO PAULO15 17 LISBOA $25 \sim 26$ JUN 2020 \\ Seminário Internacional de \\ Investigação em Urbanismo \\ Seminario Internacional de \\ Investigación en Urbanismo}

\subsection{5. Áreas Públicas com Potencial para o Lazer - Não Equipadas}

Áreas públicas com características morfológicas, ambientais e de localização que as distinguem como espaços com potencial para uso de lazer e recreação, contudo, ainda não equipadas. Conforme suas características, estas áreas podem se tornar futuras praças ou parques.

\subsection{6. Áreas de Lazer Consolidadas em Lotes Privados}

Áreas com uso de lazer e acessíveis ao público, consolidadas em lotes de posse privada, como associações comunitárias, equipamentos esportivos e outros equipamentos abertos à população em geral.

\subsection{7. Áreas de Lazer Consolidadas em Lotes Públicos não Municipais}

Áreas de lazer equipadas e acessíveis ao público consolidadas em lotes de posse de outros entes públicos, como a união federal.

\subsubsection{Estar Urbano}

Espaços equipados com mobiliário urbano de pequenas dimensões e que proporcionam a permanência no meio urbano, como os parklets, espaços com parques infantis, bancos, mesas, entre outros.

\subsection{Espaços Livres Associados à Orla}

\subsubsection{Praias}

Faixas de areia da orla pública acessíveis à toda população.

\subsubsection{Espaços Livres de Lazer e Contemplação da Orla}

Espaços livres públicos na orla com características que favorecem os usos de contemplação, lazer e recreação. Geralmente, estão situados nas proximidades das faixas de areia ou bordas d'água.

\subsubsection{Grandes Aterros}

Áreas contínuas e de grande escala originárias de aterros e que devem ser entendidas e projetadas de maneira global. São, predominantemente, abertas, com vocação para constituírem grandes parques urbanos, podendo ser ocupadas, parcialmente, por equipamentos e construções de interesse público ou coletivo. A delimitação desses elementos pode compreender, também, estruturas viárias existentes e outras áreas associadas.

\subsection{Espaços Livres de Conservação e Preservação Ambiental}

\subsection{1. Áreas Naturais Tombadas}

Áreas naturais tombadas legalmente como patrimônio natural e paisagístico do Município de Florianópolis. 


\section{XII $\quad$ SÃO PAULO $15 \sim 17 \cdot$ LISBOA $25 \sim 26$ JUN 2020

\subsubsection{Parques Ecológicos}

Áreas públicas com função prioritária de proteção ou recuperação ambiental das Áreas de Preservação Permanente ou de fragmentos florestais, às quais também se agregam funções similares às de parques urbanos compatibilizadas com atividades de lazer e recreação de baixo impacto.

\subsection{3. Áreas Públicas com Vegetação Relevante}

Áreas públicas caracterizadas pela predominância de vegetação nativa, tais como fragmentos florestais. Podem, também, incluir Áreas de Preservação Permanente. Possuem potencial para constituírem futuros parques ecológicos ou Unidades de Conservação.

\subsubsection{Unidades de Conservação}

Espaços territoriais com características naturais relevantes, legalmente instituídas pelo Poder Público, com objetivos de conservação, sendo dotadas de limites definidos em lei e colocados sob regime especial de administração.

\subsection{Espaços Livres Associados à Circulação}

\subsubsection{Alamedas e Bulevares}

Espaços públicos lineares caracterizados pela presença significativa de arborização, com função de conexão para meios não motorizado, e qualificação ambiental de áreas urbanas.

\subsubsection{Calçadões}

Espaços públicos lineares de grande largura e extensão voltados para os pedestres.

\subsubsection{Outras Áreas}

Espaços livres residuais que, por vezes, são conhecidos ou denominados como praças ou áreas verdes de lazer, mas que, por suas características morfológicas e função, não podem ser enquadradas como tal, para fins de apropriação pública. Compreende, por exemplo, algumas rótulas e canteiros da cidade.

\subsection{Espaços Livres de Uso Especial}

Grandes áreas com usos especiais e com significativa proporção de espaços livres em relação aos espaços construídos. Compreendem, por exemplo, os espaços institucionais da Base Aérea, Aeroporto e Universidade.

O presente estudo tem como foco os espaços livres com uso público de lazer, sendo que foram consideradas as categorias e subcategorias apresentadas na Tabela 01. 


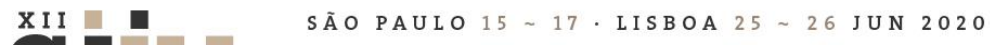 \\ Seminário Internacional de \\ Investigação em Urbanismo \\ Seminario Internacional de \\ Investigación en Urbanismo}

\begin{tabular}{|c|c|}
\hline \multirow{8}{*}{ ELLR - Espaços Livres de Lazer e Recreação } & Praças* \\
\hline & Parques Urbanos* \\
\hline & Áreas Esportivas Abertas* \\
\hline & Áreas Públicas Destinadas ao Lazer não Equipadas - Oriundas de Parcelamento* \\
\hline & Áreas Públicas com Potencial para o Lazer - Não Equipadas* \\
\hline & Áreas de Lazer Consolidadas em Lotes Privados* \\
\hline & Áreas de Lazer Consolidadas em Lotes Públicos não Municipais* \\
\hline & Estares Urbanos* \\
\hline \multirow{3}{*}{ ELAO - Espaços Livres Associados à Orla } & Praias \\
\hline & Espaços Livres de Lazer e Contemplação da Orla* \\
\hline & Grandes Aterros \\
\hline \multirow{4}{*}{ ELCPA - Espaços Livres de Conservação e Preservação Ambiental } & Áreas Naturais Tombadas \\
\hline & Parques Ecológicos* \\
\hline & Áreas Públicas com Vegetação Relevante \\
\hline & Unidades de Conservação \\
\hline \multirow{3}{*}{ ELAC - Espaços Livres Associados à Circulação } & Alamedas e Bulevares* \\
\hline & Calçadões* \\
\hline & Outras Áreas \\
\hline \multirow[t]{2}{*}{ Espaços Livres de Uso Especial } & $\begin{array}{l}\text { Grandes áreas com usos especiais e com significativa proporção de espaços livres } \\
\text { em relação aos espaços construídos. Compreendem, por exemplo, os espaços } \\
\text { institucionais da Base Aérea, Aeroporto e Universidade. }\end{array}$ \\
\hline & $\begin{array}{l}\text { *Categorias de espaços livres que cumprem a função de lazer cujos dados foram } \\
\text { utilizados nas análises espaciais dos subcapitulos } 4.3 \text { e } 4.4 \text { deste artigo. }\end{array}$ \\
\hline
\end{tabular}

Tabela 01. Classificação do Sistema de Espaços Livres de Florianópolis. Fonte: Elaboração própria

\section{RESULTADOS}

\subsection{Mapa do Sistema de Espaços Livres}

A partir da classificação dos espaços livres e seu mapeamento, foi possível ordenar e monitorar os processos de intervenção e compor uma base dados que apoie as tomadas de decisão por parte dos gestores e disponibilizar esses conteúdos via web à população (Fig. 02), como projetos em elaboração, informações descritivas e o "Mapa dos Espaços Livres", com informações georreferenciadas dos espaços livres identificados pelos levantamentos desenvolvidos, possibilitando contribuições ou questionamentos via formulário online. 


\section{SÃO PAULO 15 17. LISBOA 25 26 JUN 2020

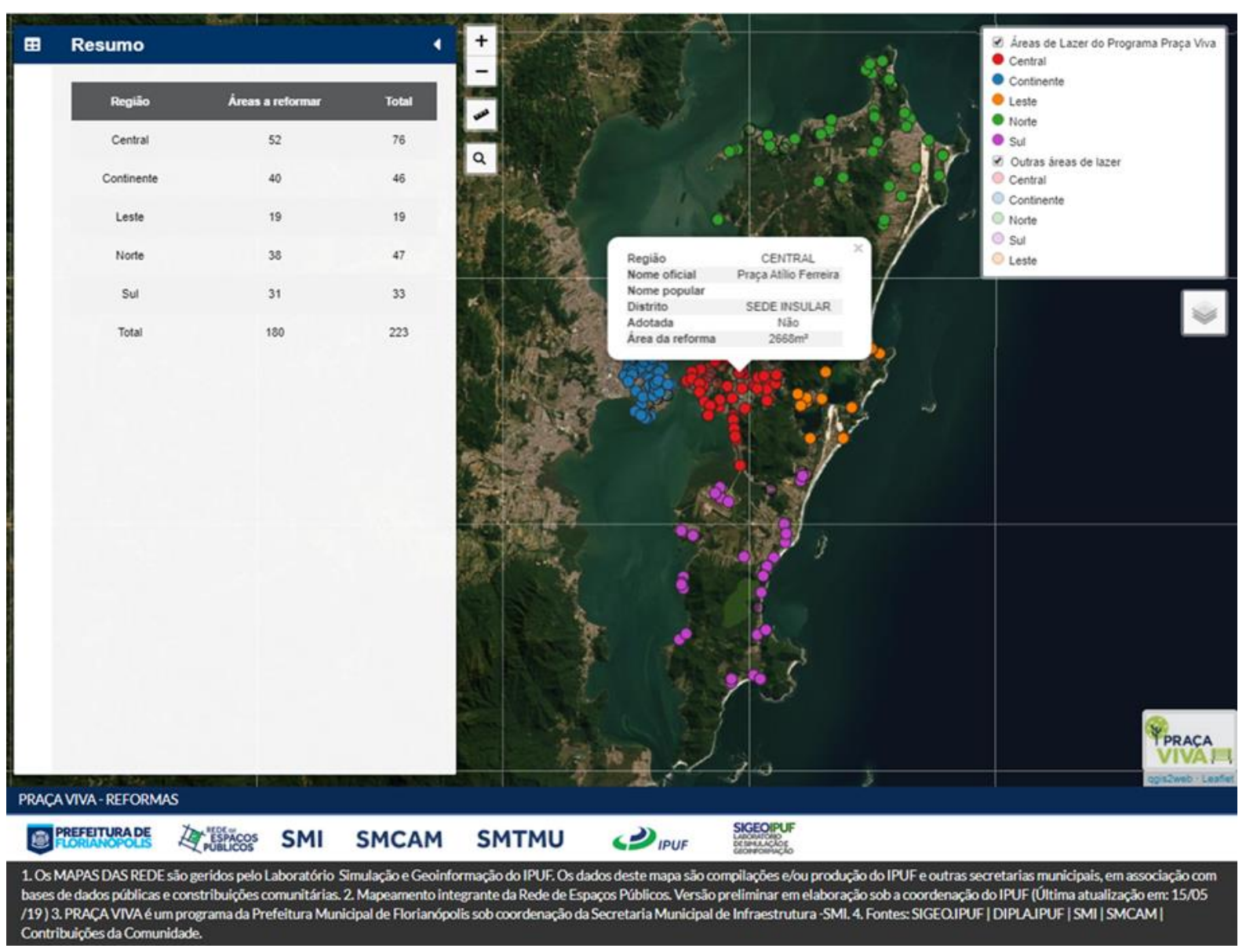

Fig. 03 Captura de tela da plataforma online Mapa Praça Viva. Fonte: (IPUF, 2019)

Desse modo, a atualização e sistematização dos dados levantados em campo, a partir da integração do trabalho entre as secretarias envolvidas, bem como a elaboração dos mapas necessários para o planejamento junto ao GEO, resultou no acompanhamento e a divulgação deste programa, dando visibilidade às áreas com uso de lazer e recreação, que não se limitam às praças e parques e possuem papel fundamental na constituição dos espaços livres de uso público reconhecidos pela população.

O Mapa Praça Viva, com o foco nas áreas com uso de lazer e recreação, permitiu a atualização da base de dados e, consequentemente, de nova versão do Mapa de Espaços Livres. Com uma base de dados de espaços com uso de lazer e recreação atualizada, foram elaboradas as primeiras análises, considerando a necessidade de identificar quais as regiões do município apresentam maior carência desses espaços e, consequentemente, quais as ações prioritárias para garantir maior equidade na sua distribuição. 


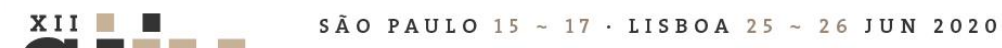 \\ Seminário Internacional de \\ Investigação em Urbanismo \\ Seminario Internacional de \\ Investigación en Urbanismo}

\section{3. Área com uso de lazer e recreação por habitante}

Com a finalidade de analisar a distribuição das áreas com uso de lazer no território, foi elaborado um mapa identificando os distritos que possuem maior oferta de espaços com uso de lazer, de acordo com a sua população. A área (em metros quadrados) de espaços com o uso de lazer, por habitante, para cada distrito pode ser visualizada na Fig. 6, graduada por escala de cor dada pelo valor obtido na razão entre a soma da metragem quadrada de todos os espaços com uso de lazer de cada distrito e a estimativa de habitantes por distrito disponibilizada pelo IBGE (2010). Os espaços com uso de lazer consolidado (C) e os espaços com potencial uso de lazer $(\mathrm{P})$, indicados numericamente no centroide de cada distrito, auxiliam a comparação entre área e quantidade dos espaços consolidados.

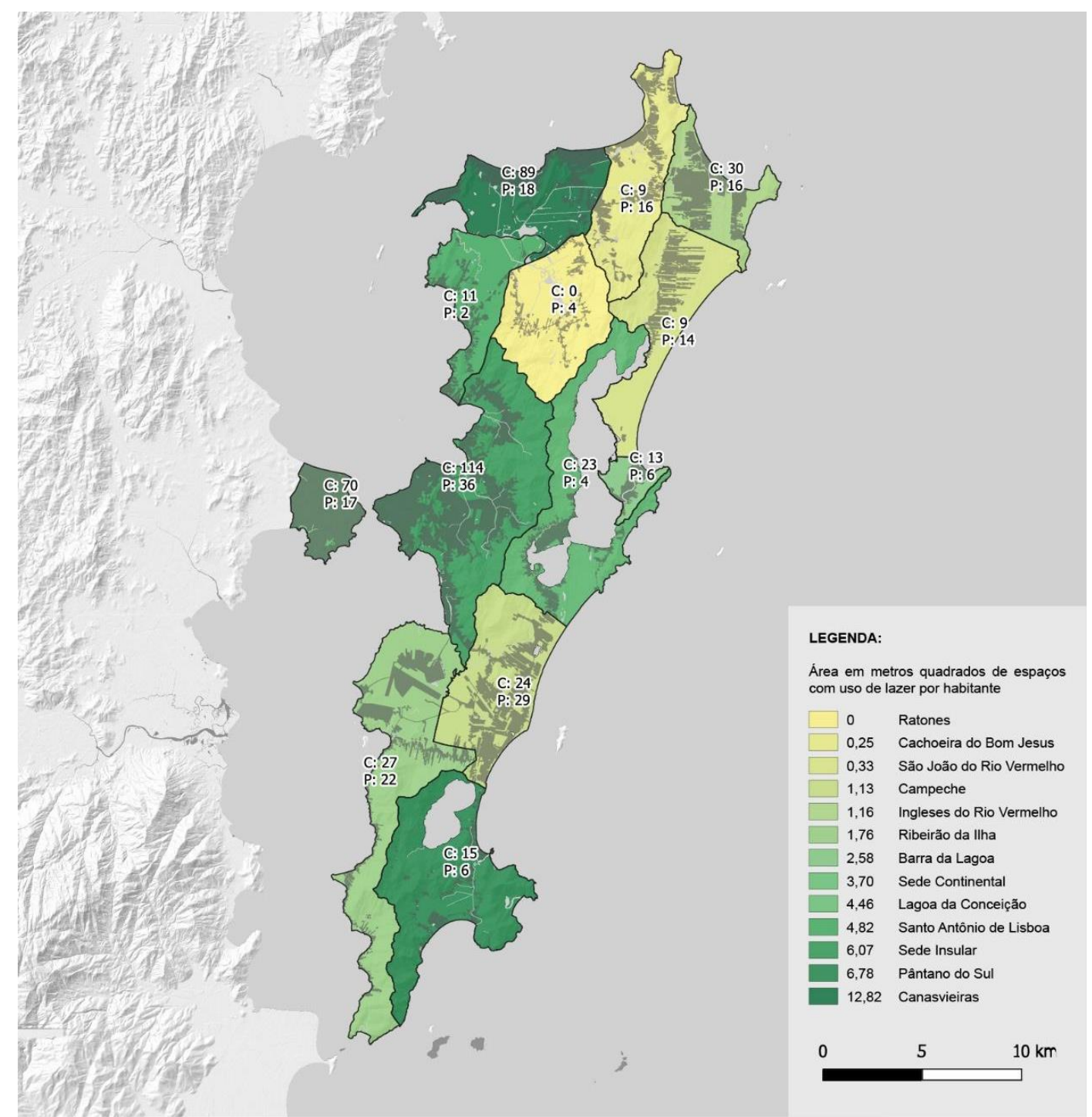

Fig. 04 Mapa de área $\left(\mathrm{m}^{2}\right)$ com uso de lazer e recreação por habitante, por distrito. Fonte: Elaboração própria com base nos dados disponibilizados pelo IBGE (2010) 


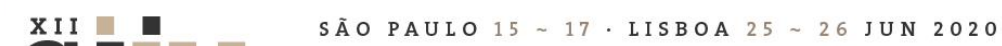

Percebe-se que a porção mais central do território do Município apresenta o maior número de áreas com uso de lazer consolidado, representada pelos distritos Sede Insular (114) e Sede Continental (70). O distrito de Canasvieiras apresenta o maior índice de área de lazer por habitante, 12,82 $\mathrm{m}^{2}$ de áreas com uso de lazer e recreação por habitante (total 89), seguido pelo distrito do Pântano do Sul, com 6,78 $\mathrm{m}^{2}$ de áreas com uso de lazer e recreação por habitante (total 15). Destaca-se a importância de incrementar novos dados qualitativos e quantitativos às análises, bem como a sua relação com o território.

Com esta etapa da análise, percebe-se que o indicador número de áreas de lazer total por distrito, dissociado da relação com a sua população, poderia gerar uma escala diferente do resultado apresentado; como exemplo, o distrito do Campeche, com o total de 24 espaços com uso de lazer e recreação e do Ribeirão da Ilha com o total de 27, estariam à frente, numericamente, do distrito do Pântano do Sul (15). Nesse sentido, este índice representa melhor a relação dos espaços com uso de lazer e recreação e a população, conforme visualizado no Gráfico 01.

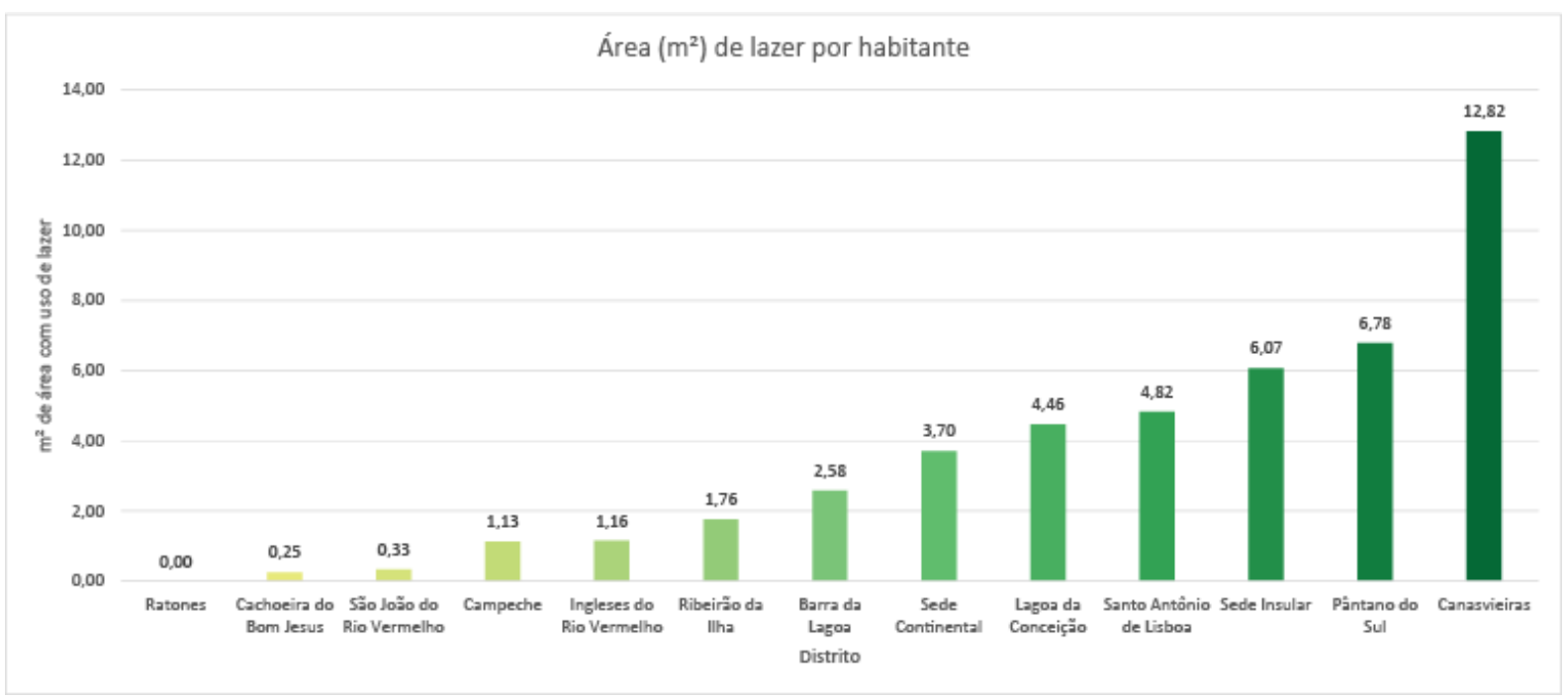

Gráfico 01 Metragem quadrada de espaços com uso de lazer e recreação por habitante, por distrito. Fonte: Elaboração própria com base nos dados disponibilizados pelo IBGE (2010)

A relação da área com uso de lazer e recreação e a população apresentada pela Fig. 4 e Gráfico 1 representa, em primeira análise, os distritos com maior carência e, portanto, com prioridade de ações e investimentos, para garantir maior equidade na distribuição de espaços com uso de lazer e recreação no município, com o distrito de Ratones, de maior carência e maior prioridade, ao Distrito de Canasvieiras, com menor carência e menor prioridade para a implantação de novos espaços com uso de lazer e recreação.

Além da relação da área com uso de lazer e recreação e a população, outros aspectos, como a distribuição destas áreas em cada distrito relacionada ao acesso da população a essas áreas, deve ser um fator a ser considerado para uma análise mais completa. 


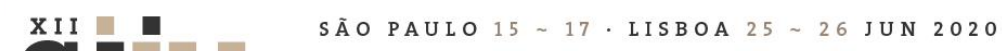 \\ Seminário Internacional de \\ Investigação em Urbanismo \\ Seminario Internacional de \\ Investigación en Urbanismo}

Nesse sentido, foi dada a continuidade das análises, buscando relacionar a disponibilidade de espaços com uso de lazer e recreação e a renda per capita, a fim de se obter outro indicador como subsídio do planejamento e das tomadas de decisão por parte dos gestores.

\subsection{Renda per capita}

A relação entre a renda per capita para cada distrito e a disponibilidade de espaços com uso de lazer e recreação em que os espaços com uso de lazer consolidado $(C)$ e os espaços com potencial para o uso de lazer $(P)$, estão indicados numericamente no centroide e a renda média é diferenciada pela escala de cores (Fig. 5).

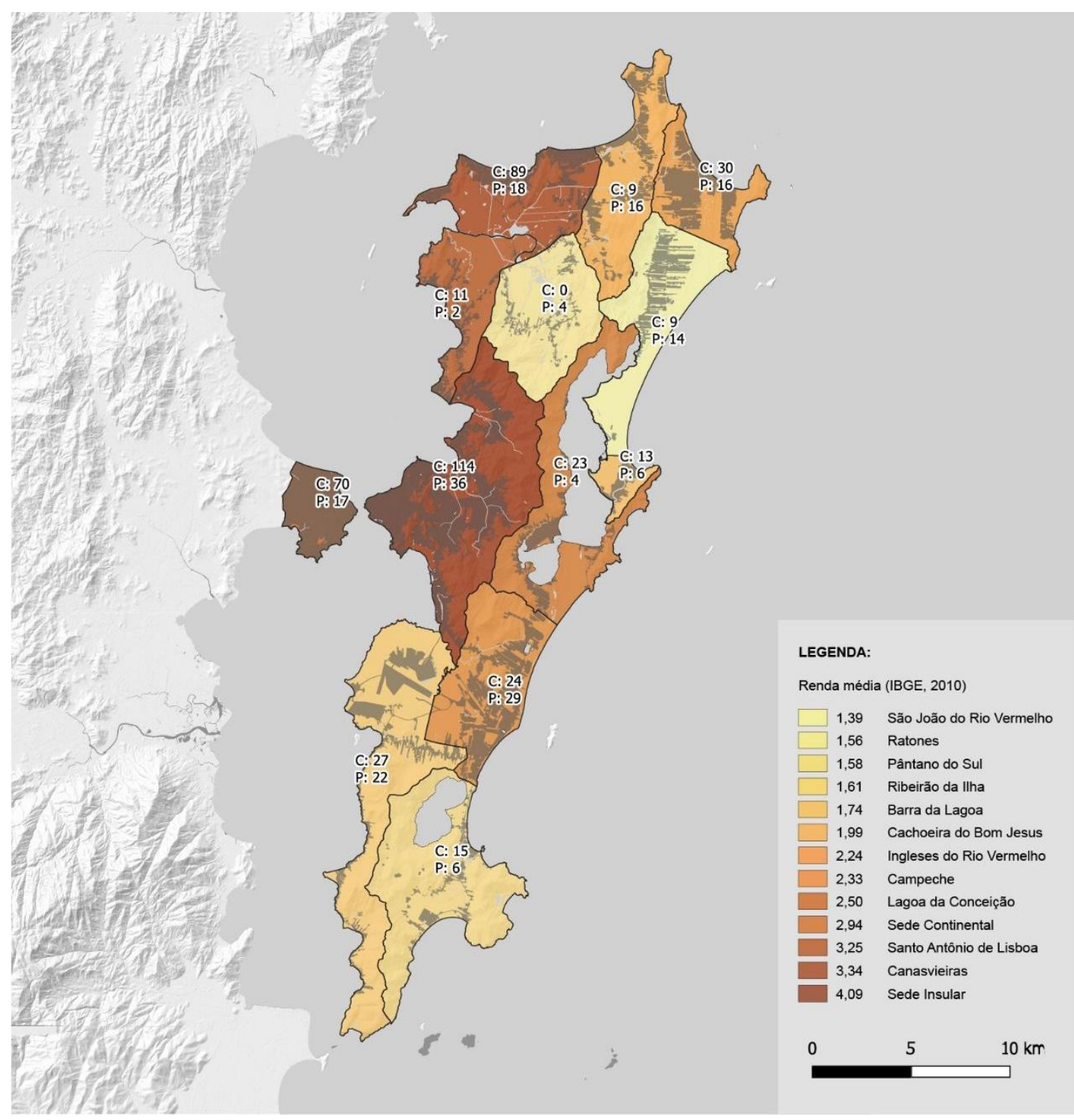

Fig. 05 Mapa de renda média em salários mínimos por distrito. Fonte: Elaboração própria com base nos dados disponibilizados pelo IBGE (2010) 


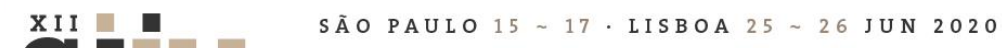 \\ Seminário Internacional de \\ Investigação em Urbanismo \\ Seminario Internacional de \\ Investigación en Urbanismo}

Com a visualização dos indicadores da renda per capita em cada distrito, constatou-se que os distritos localizados nas porções mais centrais do território possuem maior renda média, estabelecendo uma relação diretamente proporcional com o indicador de área com uso de lazer, ou seja, a infraestrutura de espaços livres públicos com uso de lazer concentra-se nas regiões com maior renda per capita e na porção mais central do território.

Outra variante para os indicadores de renda per capita foi representada pela renda média por setor censitário, para cada um dos treze distritos, disposta sobre a mancha urbanizada (Fig. 6), em que os espaços com uso de lazer consolidado (C) e os espaços com potencial para o uso de lazer (P) estão indicados numericamente no centroide e a renda média é diferenciada por escala de cores.

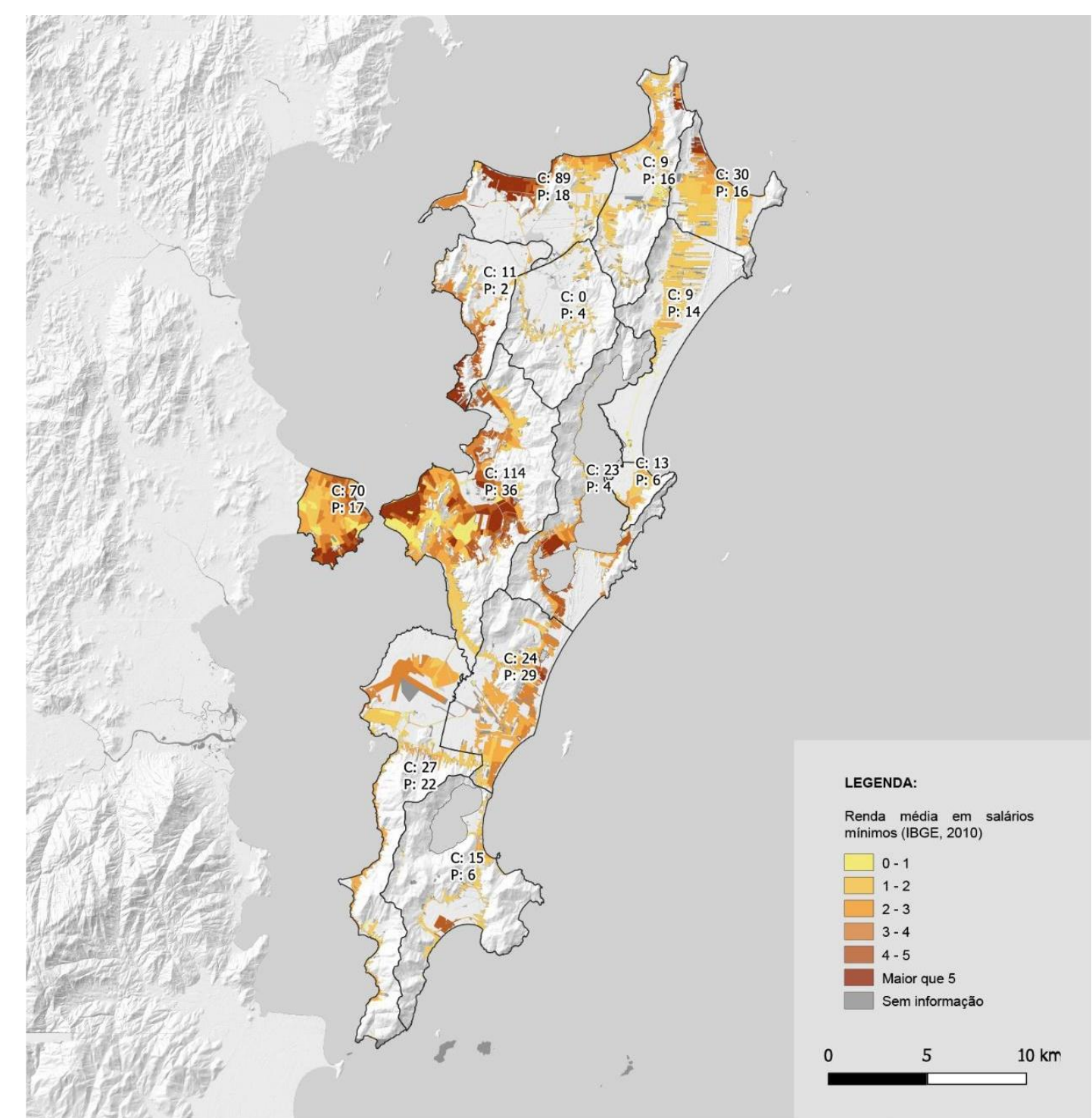

Fig. 06 Mapa de renda média em salários mínimos por setor censitário considerando a mancha urbanizada. Fonte: Elaboração própria com base nos dados disponibilizados pelo IBGE (2010) 


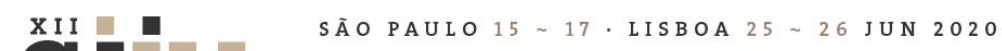 \\ Seminário Internacional de \\ Investigação em Urbanismo \\ Seminario Internacional de \\ Investigación en Urbanismo}

A distribuição do indicador de renda per capita sobre o território, considerando a mancha urbanizada, reforça a importância de qualificar os dados e a combinação de informações disponíveis para apoiar as definições de prioridades na gestão dos espaços com uso de lazer e recreação, demonstrando a relação de desigualdade espacial e socioeconômica na distribuição e oferta de áreas de lazer, bem como a necessidade de estabelecer outras relações dos indicadores de área com uso de lazer e renda por habitante, visto que o acesso a essas áreas terá relação com a malha viária, as condições de relevo e outros indicadores ainda não explorados nesta etapa de análise.

Para complementar e qualificar a análise da distribuição dos espaços com uso de lazer e recreação, foram identificados os existentes e em potencial em pontos (Fig. 7), por distrito, com a renda média por setor censitário e na mancha urbanizada.

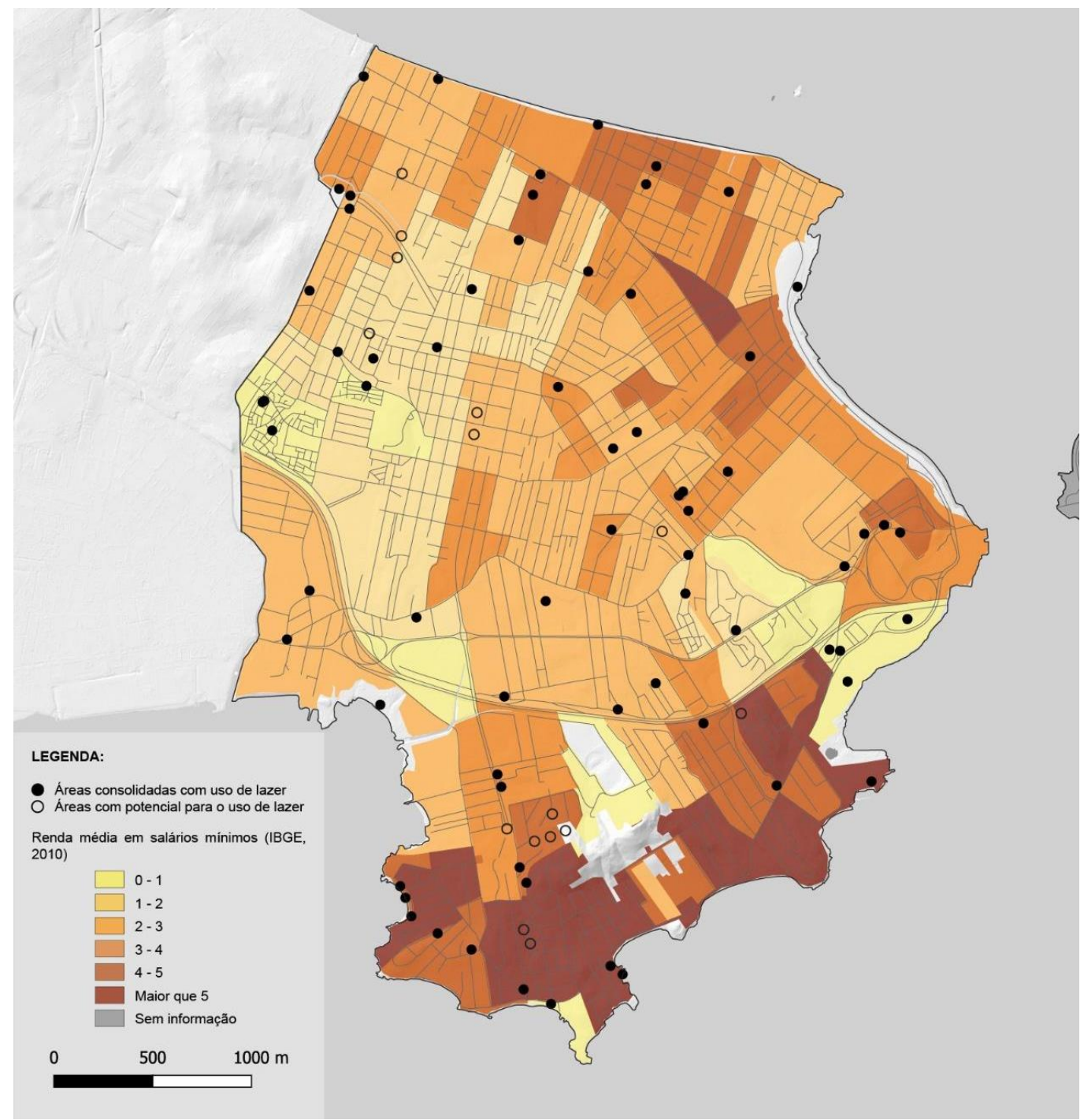

Fig. 07 Distrito Sede Continental: Mapa de renda média por habitantes por setor censitário e distribuição de espaços com uso de lazer e recreação e potenciais. Fonte: Elaboração própria com base nos dados disponibilizados pelo IBGE (2010) 



\section{SÃOPAULO $15 \sim 17 \cdot$ LISBOA $25 \sim 26$ JUN 2020}

MAGNOLI, M. (1982). Espaços Livres e urbanização: Uma introdução a aspectos da paisagem metropolitana. Tese (Livre-Docência). São Paulo. Faculdade de Arquitetura e Urbanismo, Universidade de São Paulo. - (2006). Espaço Livre - Objeto de Trabalho: Open Space. Revista Paisagem Ambiente (São Paulo), 21, 175-198.

SANTOS, M. (2006). A Natureza do Espaço: Técnica e Tempo. Razão e Emoção. São Paulo: Edusp.

\subsection{FONTES ELETRÔNICAS}

IBGE (2019). https://cidades.ibge.gov.br/brasil/sc/florianopolis/panorama (consulta: 20/02/2020)

IPUF (2018). http://espacospublicos.pmf.sc.gov.br/acoes-programas/mapasdarede/mapas-da-rede.html (consulta: 21/02/2020)

IPUF (2019). http://espacospublicos.pmf.sc.gov.br/acoes-programas/mapasdarede/reformas-pracas.html (consulta: 21/02/2020) 